\title{
Editorial: Gender Equality and Women's Empowerment in Education
}

\author{
Delfín Ortega-Sánchez ${ }^{1 *}$, Esther Sanz de la Cal ${ }^{1}$, Jaime lbáñez Quintana ${ }^{1}$ and \\ Beatrice Borghi ${ }^{2}$ \\ ${ }^{1}$ Department of Specific Didactics, Faculty of Education, University of Burgos, Burgos, Spain, ${ }^{2}$ Department of Educational \\ Sciences, Alma Mater Studiorum, University of Bologna, Bologna, Italy
}

Keywords: gender equality, teacher training, gender representation, gender stereotypes, higher education, primary and secondary education, early childhood education

\section{Editorial on the Research Topic}

\section{Gender Equality and Women's Empowerment in Education}

Current scholarly literature shows that gender inequalities are still present in the process of curricular decision making and teacher practices. These inequalities are expressed through the selection of educational content, the application of methodological strategies, the selection of teaching resources, interpersonal relationships, specific task assignments, or even seating choices within the classroom. These ongoing gender-related issues drive the need for teachers to receive specific and transversal training in this area. Such trainings should be aimed at revealing gender relations as a type of power relationship for the promotion of social change.

The literature in the field of teacher training indicates that the maintenance of gender stereotypes and biases in teacher discourses and practices reinforces the sex-gender system and, consequently, inequalities. Further research is therefore still needed to study the discourses that emerged from the teaching practices around gender. Moreover, research in this field should encourage critical reflection on teacher training plans and the teaching curriculum itself.

The adoption of coeducational approaches and the promotion of education in and for gender equality entails transforming the traditional teaching curriculum to overcome the androcentric constructive bases of historical, social, and literary knowledge. Such transformation would also motivate the incorporation of "polysemic views" in the understanding and interpretation of social reality. Even today, it is common to recognize in mainstream social communication discourses, such as advertising or audio-visual artistic expressions, clear imagery of unquestionable, allegedly identarian gender cultural patterns. The overcoming or relativization of these patterns should necessarily go through the reexamination of curricular content.

The eradication of gender inequalities requires not only the integration of all the voices that have built social knowledge but also the overcoming of gender stereotypes within the education system. It is thus essential to identify the shortcomings of teachers' training and encourage gender studies as a requisite for their curricula in order to achieve inclusive, plural, and diverse models for teaching practices.

This Research Topic includes 15 manuscripts, from nine prestigious international academic institutions (Austria, Brazil, Canada, Chile, China, Finland, Germany, Spain, and Sweden) on important topics related to the inclusion of gender inequalities in teacher training, and the analysis of this concept in the official school curriculum, materials, and teacher practices.

The experiences and socio-cultural constructions of the concept of gender constitute the explanatory core of the research problem addressed in "The Challenge of Women's Inclusion for 
Novel Teachers. Case Study in a Teacher Educator Public University". This research analyzes the representations of novice teachers of History and Social Sciences on the presence and absence of women's historical experience in their teaching practices. The research demonstrates the permanence of positivist and androcentric epistemological approaches in the teaching of History, and highlights the urgency of addressing gender inequalities as one of the most pressing social problems of our contemporaneity. In this vein, "Classical Sociology Through the Lens of Gendered Experiences" seeks to promote discussion on the mediating role of gendered experiences in classical sociology's theories of the move towards modern society. This study evidences the constructive relativity of social knowledge and its consequences for sociological teaching and learning.

From the conception of a socio-constructive nature of sexism, the research "Intersections Around Ambivalent Sexism: Internalized Homonegativity, Resistance to Heteronormativity and Other Correlates" explores the levels of internalized sexism and homonegativity, and the resistance to heteronormativity of Spanish psychology students. Its results are consistent with those obtained in the study "Evaluation of Sexist and Prejudiced Attitudes Toward Homosexuality in Spanish Future Teachers: Analysis of Related Variables", focused on the analysis of sexist and prejudiced attitudes toward homosexuality of future Spanish teachers. Both studies show the influence of factors such as political ideology, gender identity and sexual orientation on students' beliefs and perceptions. They also point out the need to advance in the eradication of discrimination based on sex and sexual diversity in the training of future professionals, and the implementation of intersectional approaches to understand the sexist construct.

The consequences of the invisibility of female referents in education and, therefore, of models on which to build plural and empowered identities, derives from the limitations inherent in traditional gender expectations and attributions. The educational hegemony of these attributions, the basis of the study "Nine Contradictory Observations About Girls' and Boys' Upbringing and Education-The Strength-Based Approach as the Way to Eliminate the Gender Gap", continue to limit the potential expectations and talents of girls. Through "nine contradictory observations", this article directs its proposal towards a "strengthbased approach" as a way to eradicate the gender gap. Along these lines, "Mindfulness and Empathy: Mediating Factors and Gender Differences in a Spanish Sample" highlights the lack of studies aimed at analyzing the potential moderating role of gender in the development of empathic skills.

The research production around the gender gap and gendersegregated differentiation seems not to have received the desired impact in educational social spaces. From this perspective, on the one hand, the article "Differentiations in Visibility-Male Advantages and Female Disadvantages in Gender-Segregated Programmes" starts from the differential articulation of inter- and intra-group visibility, by gender, in students, underrepresented in their programmes. On the other hand, the works "Distributing Feedback Wisely to Empower Girls in STEM" and "Girls in STEM: Is It a Female Role-Model Thing?" highlight the still distant presence of women in the development of
STEM professions, a circumstance originating in the educational context and influenced, therefore, by traditional gender models and by social factors that have an impact on the construction of personal identities, as also evidenced by the work "What Dominates the Female Class Identification? Evidence From China".

These constructed identities are revealed in the underestimation of the self-efficacy of secondary school students regarding their competences in STEM subjects, as shown in the work "Parent and Teacher Depictions of Gender Gaps in Secondary Student Appraisals of Their Academic Competences". Consequently, the analysis of selfefficacy, expectations of results, interest in STEM areas and the intervention in the classrooms of plural female role models are proposed as necessary working spaces to redirect this trend. These results are completed with the analysis of the potential influence of gender stereotypes in biased student evaluations of teaching in "Gender Stereotypes in Student Evaluations of Teaching".

From the area of Brazilian physical education, "Gender Participation and Preference: A Multiple-Case Study on Teaching Circus at PE in Brazilians Schools" reports on the elective influence of Primary Education teachers in the assignment of circus physical activities according to gender, extensible to the sports activities of traditional teaching. In order to advance in critical and emancipatory training proposals in gender equality in this area, "Breaking Cultural 'Taboos' About the Body and Gender: Brazilian Students' Emancipation From a Thematic Perspective of School Physical Education" stresses the importance of teaching programs oriented to the cultural construction of the differential concept of the body. From this perspective, the work "REFLECT-A Teacher Training Program to Promote Gender Equality in Schools" emphasizes the hegemonic role of socializing agents in maintaining the status quo of gender stereotypes in education and in the future professional development of men and women. As a response to the permanence of the sex-gender system, and to the evidence of the influence of teachers' attitudes and practices in the promotion of truly coeducational educational environments, this program, aimed at future teachers of Secondary Education, aims to contribute, in a sustainable way, to gender equality from the educational spaces of subjective action (such as self-efficacy), and objective action (teaching methods and knowledge).

\section{AUTHOR CONTRIBUTIONS}

All authors listed have made a substantial, direct, and intellectual contribution to the work and approved it for publication.

\section{FUNDING}

This Research Topic was completed with the main support of the Research Group Recognized in Didactics of History and Social Sciences (DHISO) (cod. 137), directed by Prof. Dr. Delfín Ortega-Sánchez (University of Burgos, Spain). Likewise, it has also been carried out within the framework of the projects Teach and learn to interpret contemporary problems and conflicts. What do social sciences contribute to the formation of a critical global citizenship? (EDU2016-80145-P), financed by the Ministry of Economy and Competitiveness (Spanish Government), and Future Education and Democratic Hope. 
Rethinking Social Studies Education in changing times (PID2019107383RB-I00), financed by the Ministry of Science, and Innovation (Spanish Government).

Conflict of Interest: The authors declare that the research was conducted in the absence of any commercial or financial relationships that could be construed as a potential conflict of interest.

Publisher's Note: All claims expressed in this article are solely those of the authors and do not necessarily represent those of their affiliated organizations, or those of the publisher, the editors and the reviewers. Any product that may be evaluated in this article, or claim that may be made by its manufacturer, is not guaranteed or endorsed by the publisher.

Copyright () 2022 Ortega-Sánchez, Sanz de la Cal, Ibánez Quintana and Borghi. This is an open-access article distributed under the terms of the Creative Commons Attribution License (CC BY). The use, distribution or reproduction in other forums is permitted, provided the original author(s) and the copyright owner(s) are credited and that the original publication in this journal is cited, in accordance with accepted academic practice. No use, distribution or reproduction is permitted which does not comply with these terms. 